\title{
Environmental Niche Modelling with Desktop GARP for Wild Origanum vulgare L. (Lamiaceae) in Armenia
}

\author{
Armine Abrahamyan, Arvids Barsevskis \\ Institute of Systematic Biology, Daugavpils University, Daugavpils, Latvia, LV 5400 \\ Arm_abrahamyan@yahoo.com, Armine_Abrahamyan@ru.lv
}

\begin{abstract}
Predicting species' distributions has became one of the significant components of conservation biology in recent years. During the study, GARP (genetic algorithm) has been identified the key modelling technique for determining Origanum vulgare L. (Oregano, Lamiaceae) environmental niche in the Republic of Armenia. For over three consecutive years, from 2010-2013 it has been created relevant environmental layers through ESRI ArcGIS programs to be used with the plant actual distribution (occurrence records) as input data of GARP. In the result of the study, it has been produced the fundamental and realized niche and predictive habitat distribution of $O$. vulgare L. with Bitmap under the global climate change. Produced Bitmap illustrates that Oregano distributions would decrease mostly in the central regions due to environmental deterioration and climate change. This research could provide significant data for future conservation planning of wild Oregano in the Republic of Armenia.
\end{abstract}

Keywords: artificial intelligence framework, Bitmap, predictive distribution, realized niche.

\section{INTRODUCTION}

Predicting species' distributions has become an important component of conservation planning in recent years, e.g. searching for rare or endangered species, planning new conservation areas, assessing the impact of human activities on biodiversity, predicting the impacts of climate change on species' distribution, preventing the spread of invasive species etc.. In fact, wide variety of modelling techniques have been developed for this purpose $[2 ; 5]$.

Environmental niche modelling refers to the process of using computer algorithms to predict the distribution of species in geographic space on the basis of a mathematical representation of their known distribution in environmental space.

This research work has been carried out for over three consecutive years, from 2010-2013. During the study, Desktop GARP has been identified the key modelling technique for determining Origanum vulgare L. (Oregano, Lamiaceae) environmental niche or predictive habitat distribution in the Republic of Armenia.

During the study, the model is applied for funding associations between environmental variables and known wild Oregano' occurrence records to identify environmental conditions, within which populations can be maintained. The spatial distribution of environments that are suitable for this wild valuable plant can then be estimated across a study region.

This approach has proven valuable for generating biogeographically information that can be applied across a broad range of fields, including conservation biology, ecology and evolutionary biology.

\section{MATERIALS AND METHODS}

Potential distribution modelling is the process of combining occurrence data (locations where the species has been identified as being present or absent) with ecological and environmental variables (such as temperature, precipitation, and vegetation) to create a model of the species' requirements [1]. The correlative approach and presence data (actual distribution of populations) has been identified the key elements of Desktop GARP during the study. Correlative models of Desktop GARP aim to estimate the environmental conditions that are suitable for a species/populations by associating known species' occurrence records or actual distribution with suites of environmental variables that can reasonably be expected to affect the species' physiology and probability of persistence. In fact, this approach is applied to determine the plant fundamental niche, and realized niche. The following diagram shows a hypothetical situation where a species distribution is controlled by just two environmental variables: temperature and moisture.

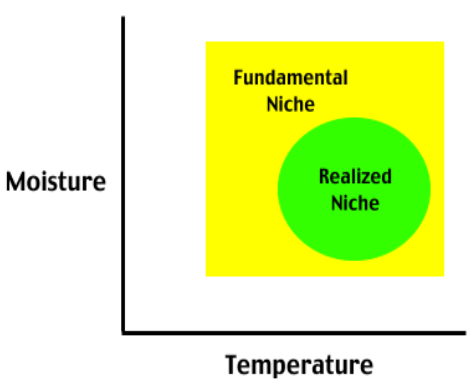

Figure 1: The green and yellow areas describe the combinations of temperature and moisture that the species requires for survival and reproduction in its habitat. 


\section{Abrahamyan A., Barsevskis A. ENVIRONMENTAL NICHE MODELLING WITH DESKTOP GARP FOR WILD ORIGANUM VULGARE L.(LAMIACEAE) IN ARMENIA}

This resource space is known as the fundamental niche. The green area describes the actual combinations of these two variables that the species utilizes in its habitat. This subset of the fundamental niche is known as the realized niche. While suitable environmental conditions determine a species' fundamental niche, biological factors such as competition tend to reduce the fundamental niche into the realized niche [6]. The potential distribution of a species can be seen as the geographical expression of its realized niche at a particular time (i.e., where there is a fulfillment of both abiotic and biotic requirements) [5].

The principal steps required to build and validate a correlative species' distribution model are outlined in Figure 2. Two types of model input data has been applied: 1) known species' occurrence records (actual distribution); and 2) a suite of environmental variables. 'Raw' environmental variables, such as daily precipitation records collected from weather stations, are often processed to generate model inputs that are thought to have a direct physiological role in limiting the ability of the species to survive. Correlative species' distribution models rely on observed occurrence records for providing information on the niche and distribution of a species.

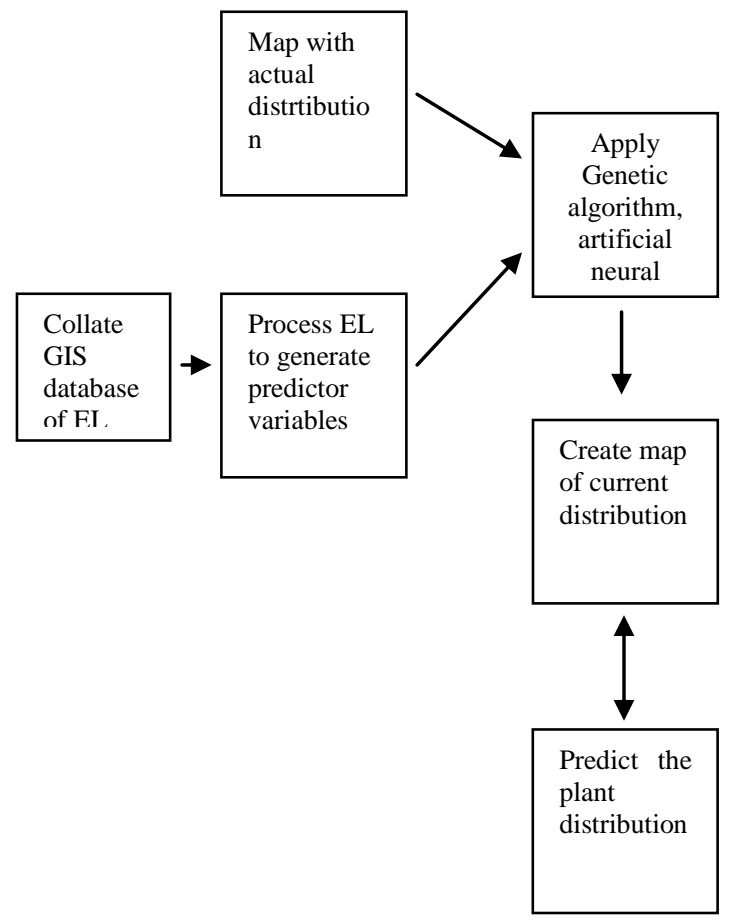

Fig.2: Flow diagram detailing the main steps required for building and validating a correlative approach of distribution model, where EL refers to Environmental Layers.

So, DesktopGarp as a software package for biodiversity and ecologic research allows us to predict and analyze wild Oregano distributions in the RA. Based on artificial intelligence framework, GARP is capable of creating ecological niche models of wild Oregano with the environmental conditions under which the plant should be able to maintain populations. For input, GARP uses a set of point localities where the plant is known to occur and a set

of geographic layers representing the environmental parameters that might limit the species' capabilities to survive [3]. For instances, GARP contains a window where we have specified all the parameters and data to be used in the experiment. Below is a sample of the interface.

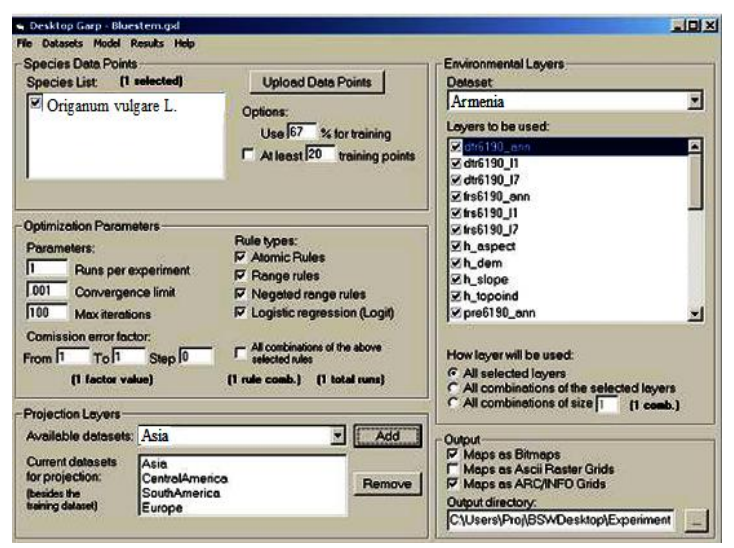

Fig.3: Desktop Garp parameter

In fact, environmental layers typically represent abiotic conditions by representing temperature, precipitation, radiation, wind, evaporation, topography, soil moisture, and vegetation coverage. Environmental rasters have been produced from satellite data, weather station data (by interpolation of raw data) and some other set of measurements.

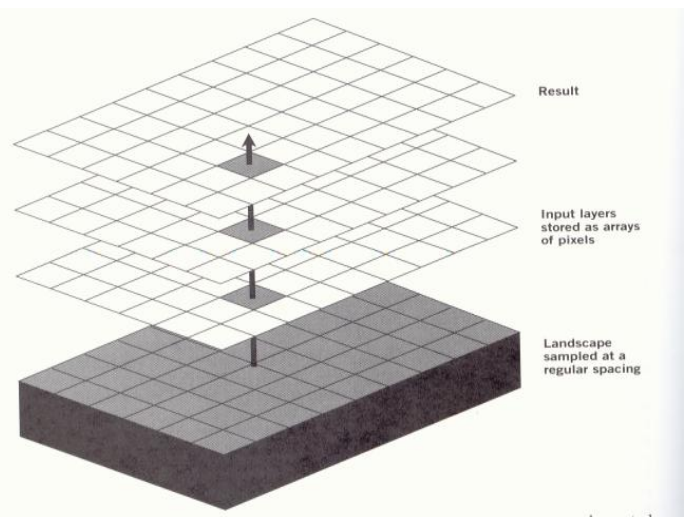

Fig4: Environmental layers

During the study, ESRI ArcGIS program is applied to produce relevant environmental layers. For example, the precipitation or temperature layers and also, to recorded the locations of the populations.

\section{RESULTS AND DISCUSSION}

A crucial consideration that is overlooked in the study time is exactly what component of a plant' niche is being modelled distinguish three broad categories of factors that determine of Oregano distributions over the country: abiotic environmental factors, biotic factors concerning interactions among species, and factors that affect the ability of species to disperse to different areas.

In the result of the study, it has been determined the ratio between fundamental, realized niche and the 


\section{Abrahamyan A., Barsevskis A. ENVIRONMENTAL NICHE MODELLING WITH DESKTOP GARP FOR WILD ORIGANUM VULGARE L.(LAMIACEAE) IN ARMENIA}

actual distribution of wild $O$. Vulgare $\mathrm{L}$. in the Republic of Armenia (Figure 5). Environmental niche components of used variables in the distribution models are approved to be the direct drivers of Oregano distributions, which means that Desktop Garp is more closely resemble the realized distribution than the fundamental distribution. In the following diagram has been shown it.

\section{Fundamental and Realized Niche of Oregano} vulgare L. in Armenia, 2012

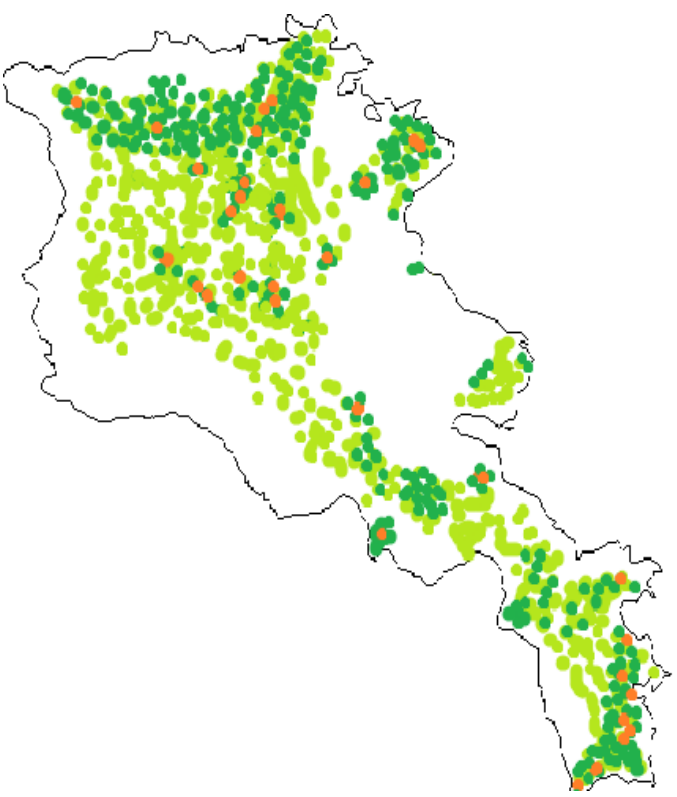

Figure 5: Fundamental niche encompasses yellow points, realized/potential niche green and the actual distribution comprises brown points.

Also, it has been predicted future distributional pattern of wild Oregano in Armenia under global climate change, environmental deteriorations and other threats in accordance with relevant input data e.g. environmental layers appertain to global climate change.

In the following figure it is illustrated Bitmap or predicted map of wild Origanum vulgare L. distributions.

Wild Oregano vulgare L. Predicted Distributions

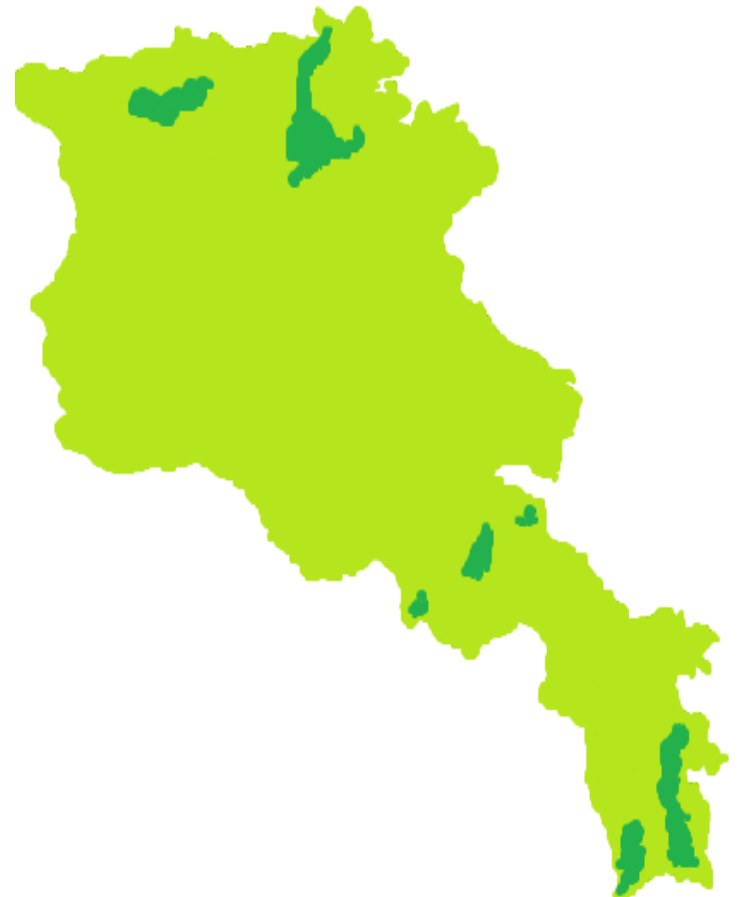

Figure 6: Bitmap of Oregano in Armenia up to 2100 under global climate impact.

According to the produced Bitmap, the vulnerability $O$. Vulgare L. would particularly increase in the central regions of the country. These territories were identified to be comparatively stressful environments under global climate changes and anthropogenic threats. Likewise, it has been anticipated much more negative impact of the climate change into populations distributions in the central regions of the country by comparison with northern and south regions.

Generally, in the south and north regions wild oregano future distribution might increase, which is also obvious from figure 5, where realized/ potential niche is widely distributed in these regions. In addition, realized niche is comprising that portion of fundamental niche from which the plant is not excluded due to biotic competition encapsulated with set of favorable environmental conditions.

So, the populations from south and north regions would not suffer so much from the global warming. Also, in these regions populations are more sustainable and mostly exposed increase of their sizes and abundance during the study period. There could be many different factors affecting on the increase of populations 'sizes, such as biological characteristics of the plant, favorable environmental and habitat conditions, biotic interactions among the $O$. Vulgare L. and other plants, antropogenetic threats, environmental deteriorations, habitat loss etc. 


\section{Abrahamyan A., Barsevskis A. ENVIRONMENTAL NICHE MODELLING WITH DESKTOP GARP FOR WILD ORIGANUM VULGARE L.(LAMIACEAE) IN ARMENIA}

In fact, one of the key elements that might affect on future distributions of wild $O$. Vulgare L. populations over the country is the mentioned factors interactions along with global climate change impact. For instances, populations would increase in their sizes and would cover new territories in the south and north regions not only because of favorable habitat environment (e.g. with slight mechanical structure and relatively high humus concentration bearing soils) but also because of the fact that the global climate change would not arise here habitat distortions as much as in the central regions.

In fact, precipitations decrease will occur in higher level here then the other regions, the increase of temperature with $4-5^{\circ} \mathrm{C}$ again is recorded the highest one, droughts also will occur more often here then the other regions according to $\mathrm{B}_{2}$ scenario (2030-2100 of global climate change,) etc.

\section{CONCLUSION}

In conclusion, it has been determined wild Oreganum vulgare $\mathrm{L}$. fundamental and realized niche. During the environmental niche modeling, variables components has been identified the key directives for Desktop Garp. That is why, it is more closely resemble the realized distribution than the fundamental distribution.

Also, the produced Bitmap with the predictable habitats illustrates that Oregano distributions would decrease mostly in the central regions under global climate change.

In fact, these territories were identified to be comparatively stressful environments. On the other hand, the plant distribution in the North and South regions would not suffer that much from the climate change and environmental deterioration.
This research provides significant data that can be used for future conservation planning of this unique culinary and medicinal plant in the Republic of Armenia.

\section{ACKNOWLEDGMENTS}

This study has been supported by ESF within the project "Support for the implementation of doctoral studies at Daugavpils University, $2^{\text {nd }}$ stage". Nr. 2012/0004/1DP/1.1.2.1.2/11/IPIA/VIAA/011.

\section{REFERENCES}

[1] Anderson RP, Lew D, Peterson AT, Evaluating predictive models of species' distributions: criteria for selecting optimal models. Ecol Model, 2003, 162:211-232

[2] Guisan, A., and W. Thuiller. 2005. Predicting species distribution: Offering more than simple habitat models. Ecology Letters 8, 9931009http://www.treehugger.com/cars/e-cars-and-busescharge-magically-with-underground-induction.html

[3] Huntley, B., P.M. Berry, W. Cramer, and A.P. Mcdonald. Modelling present and potential future ranges of some European higher plants using climate response surfaces. Journal of Biogeography 22, 967-1001, 1995

[4] IUCN, WHO, WWF (1993). Guidelines on the Conservation of Medicinal Plants, IUCN, Gland, Switzerland, $50 \mathrm{p}$.

[5] Peterson AT, Uses and requirements of ecological niche models and related distributional models.Biodiversity Informatics, 2006, 3:59-72.

[6] Peterson A.T. \& Cohoon K.P. (1999). Sensitivity of distributional prediction algorithms to geographic data completeness. Ecological Modelling, 117, 159-164.

[7] Austin, M. P. et al. 1990. Measurement of the realized qualitative niche: environmental niches of five Eucalyptus species._Ecol. Monogr. 60: 161_177.

[8] Taghtajyan A. L., Flora of Armenia, VIII sector, National Academy of Sciences of Armenia, Botanical Institute, Yerevan, 1987, Pages 418

[9] www.gbif.org

[10] http://www.ncdc.noaa.gov/paleo/paleo.html

[11] http://www.worldclim.org/

[12] http://www.ipcc-data.org/ 